\title{
Analysis of the effectiveness of using state observers in the control system of the traveling mechanism of the bridge crane trolley
}

\author{
Viktor Meshcheryakov ${ }^{1, *}$, Tatyana Sinyukova ${ }^{1}$, Alexey Sinyukov ${ }^{1}$, and $O . V$. Vladimirov $^{2}$ \\ ${ }^{1}$ Electric Drive Department, Lipetsk State Technical University, Lipetsk, Russia \\ ${ }^{2}$ Kazan State Power Engineering University, Kazan, Russia
}

\begin{abstract}
This article discusses the frequency control systems of an asynchronous electric drive with various types of observers that are promising for the movement mechanism of the bridge crane trolley. As a result of the analysis of existing control systems for asynchronous motors, it was revealed that the most relevant for use at the object under consideration is a system with direct torque control. To improve the classical control system, it is proposed to introduce a state observer into it. Sensorless control systems, in comparison with other systems, make it possible to reduce the dimensions of both a separate mechanism and the device as a whole, and reduce its cost. The use of observers leads to an increase in the reliability of an object without complicating its design. For the functioning of systems of this type, only data from the current and voltage sensors built into the frequency converter are used.
\end{abstract}

\section{General information}

Lifting machines, which include cranes, are the objects of common use. Efficiency of operation of each mechanism of the crane depends on the control system [1-15].

In this paper, the mechanism of movement of the trolley of an overhead crane is considered, on which an asynchronous motor with a squirrel-cage rotor controlled by a frequency converter is installed, the control system used is direct torque control.

Systems with direct torque control allow for highquality regulation of a number of indicators, featuring high speed. To increase the reliability of the classical system of direct torque control, it is proposed to introduce state observers into it.

The observer is a structured object, the principle of which is the estimation of an unknown parameter according to measurable data without installing additional sensors.

Based on the studies carried out, it was revealed that observers are relevant for consideration from different positions:

- non-adaptive;

- adaptive;

- full-order observers.

\subsection{Electric drive cycle}

At the initial stage, a standard system for direct torque control of an induction motor in the Matlab environment was assembled. For modeling, a typical cycle of the electric drive of the crane trolley was adopted.After loading the load onto the mechanism, the cart with the load moves to a given point. Further, after unloading, the empty cart is returned to its original position. Thus, first, the loaded (by $20 \%$ of the rated torque) electric drive accelerates at a given rate to the rated speed (I, VI), which is maintained for 1 second (II, VII), after which the electric drive is decelerated (III, VIII) until it stops completely (IV, IX). Then the load is shed (V), and this process is repeated, but already for idle, because the cart returns to its original position without load. The presence of the intensity generator provides limitation of jerks, accelerations and smooth movement during acceleration and deceleration, which is one of the main requirements for the electric drive of the crane trolley. The simulation results are shown in Fig. 1.

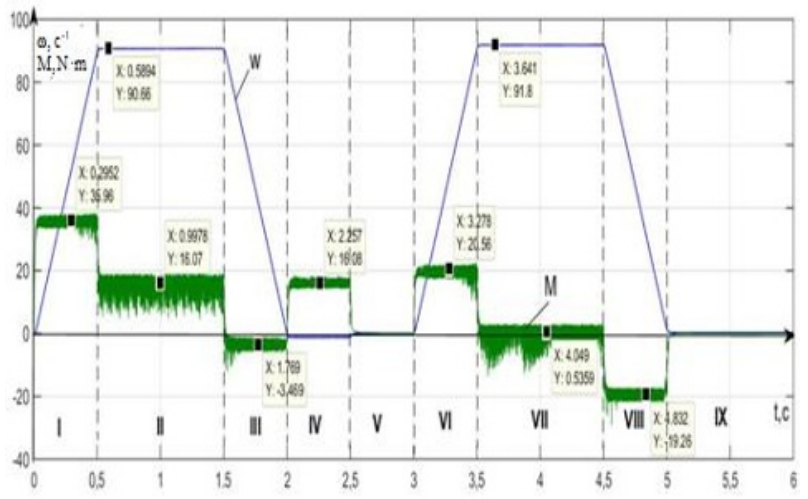

Fig. 1.Graphs of the speed and torque versus time for the direct torque control.

\footnotetext{
*Corresponding author: mesherek@yandex.ru
} 


\subsection{System with a non-adaptive observer}

The A mathematical model in the Matlab environment of a system with direct torque control is presented; containing a state observer is shown in Fig. 2.

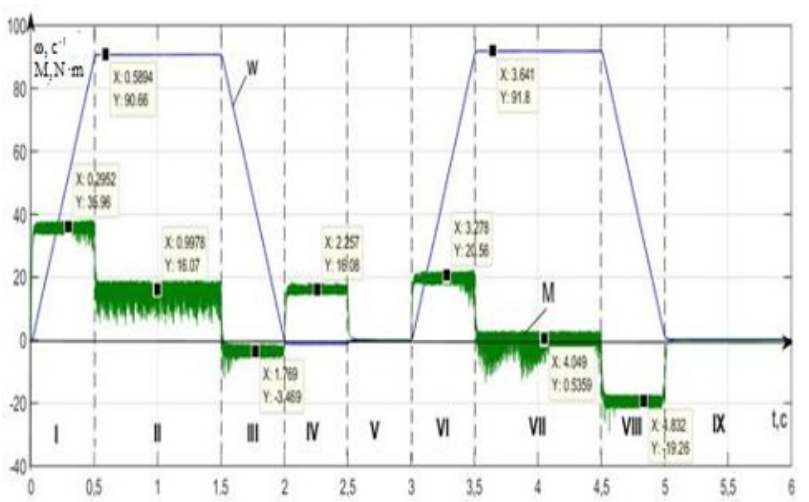

Fig. 2.Sensorless control system.

\section{Systems with different types of observers}

\subsection{Systems with a non-adaptive observer}

A non-adaptive observer is the simplest type of observer in structure, in which the estimation of unknown quantities is based on the mathematical description of an induction motor in a fixed coordinate system. The presence of speed in the rotor voltage equations allows you to determine its value through the values of other variables. The block diagram of a non-adaptive observer is shown in Fig. 3, its implementation in the Matlab environment is shown in Fig. 4.

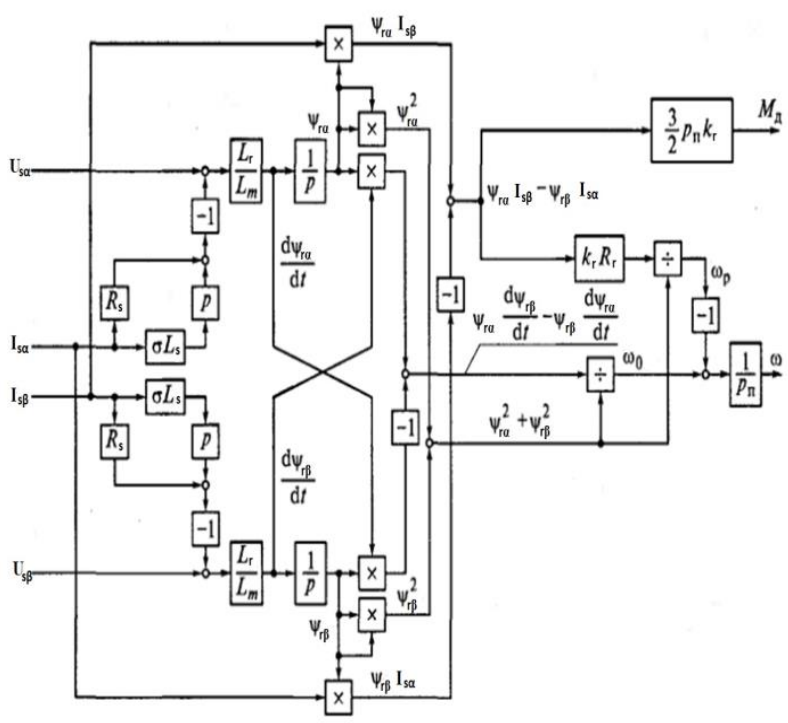

Fig. 3.Structural diagram of the observer.

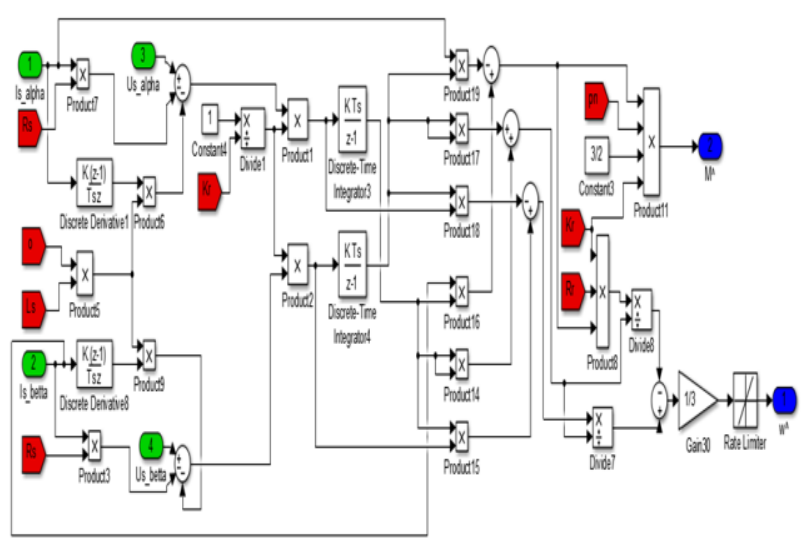

Fig. 4.Simulation model of a non-adaptive observer.

In fig. 5 shows the blocks for setting the initial parameters and coefficients.

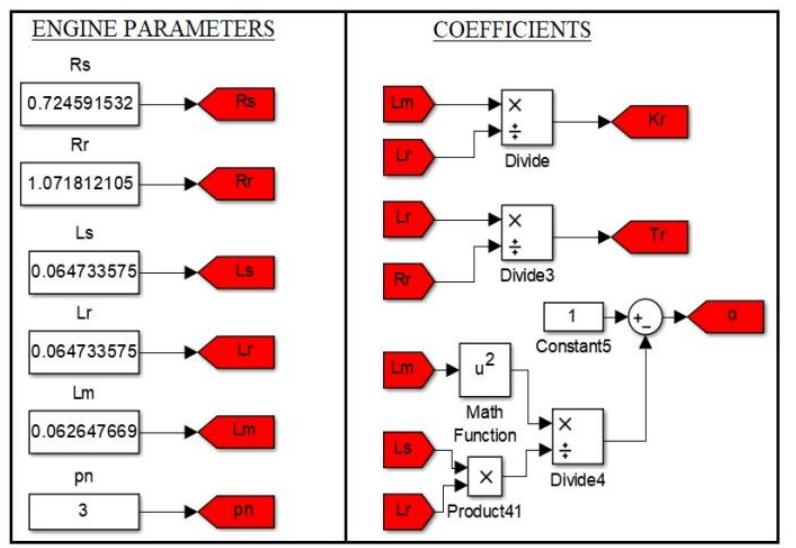

Fig. 5.Parameter blocks.

\subsection{Adaptive Observer System}

An adaptive observer is an adaptive system with a reference (master) and adaptive models. Models can be obtained from the mathematical description of a squirrelcage induction motor in a fixed Cartesian coordinate system. Often, the stator model is taken as the reference (master) model, and the rotor model is taken as the adaptive model. The structural diagram of the adaptive observer is shown in Fig. 6, its implementation in the Matlab environment is shown in Fig. 7.

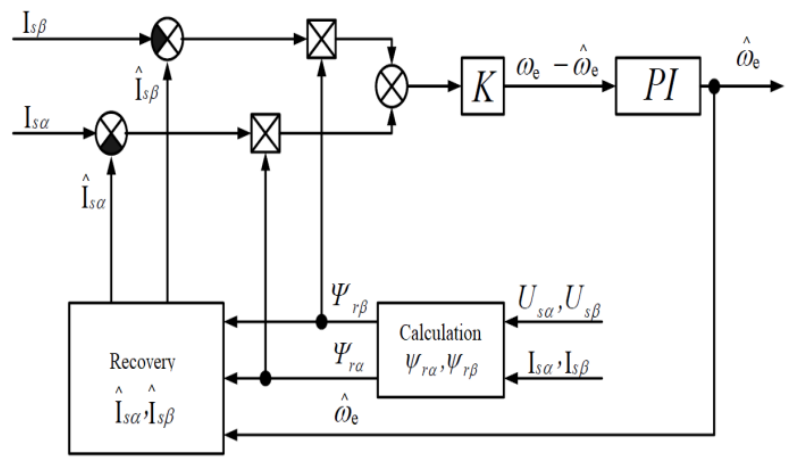

Fig. 6.Structural diagram of the observer. 


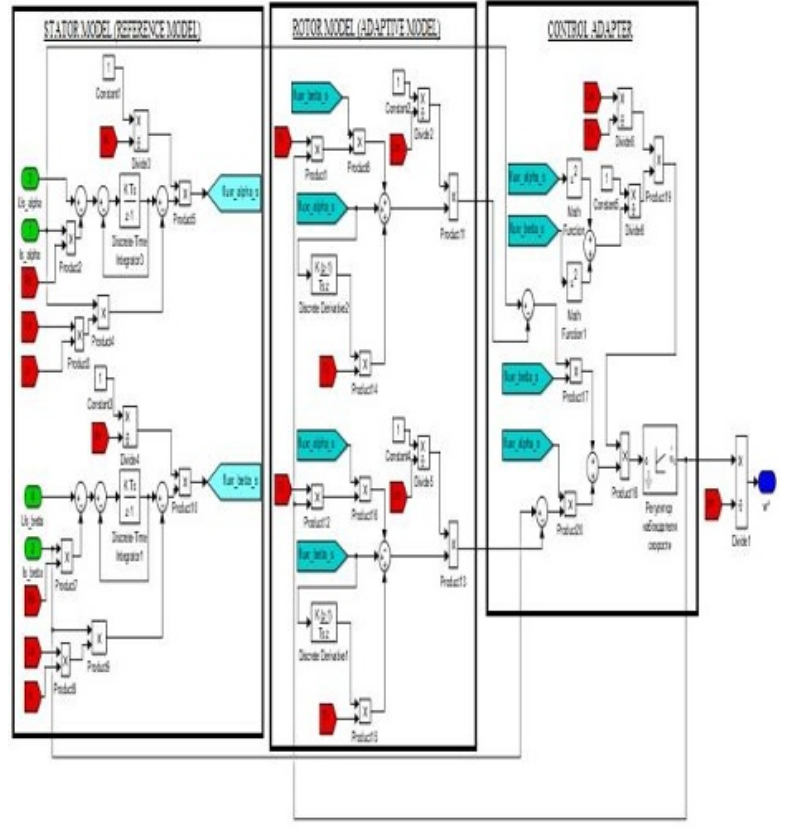

Fig. 7.Adaptive Observer Simulation Model.

\subsection{Full-order observer system}

In full-order observers, the engine itself is taken as the reference model, and the Full Order Observer (FOO) is the adaptable model. The full-order observer model is based on a system of equations describing electromagnetic processes in an asynchronous motor in a fixed $\alpha-\beta$ coordinate system.

The block diagram of a full-order observer is shown in Fig. 8, its implementation in Matlab is shown in Fig. 9.

The structure of the blocks of calculated coefficients is shown in Fig. 10.

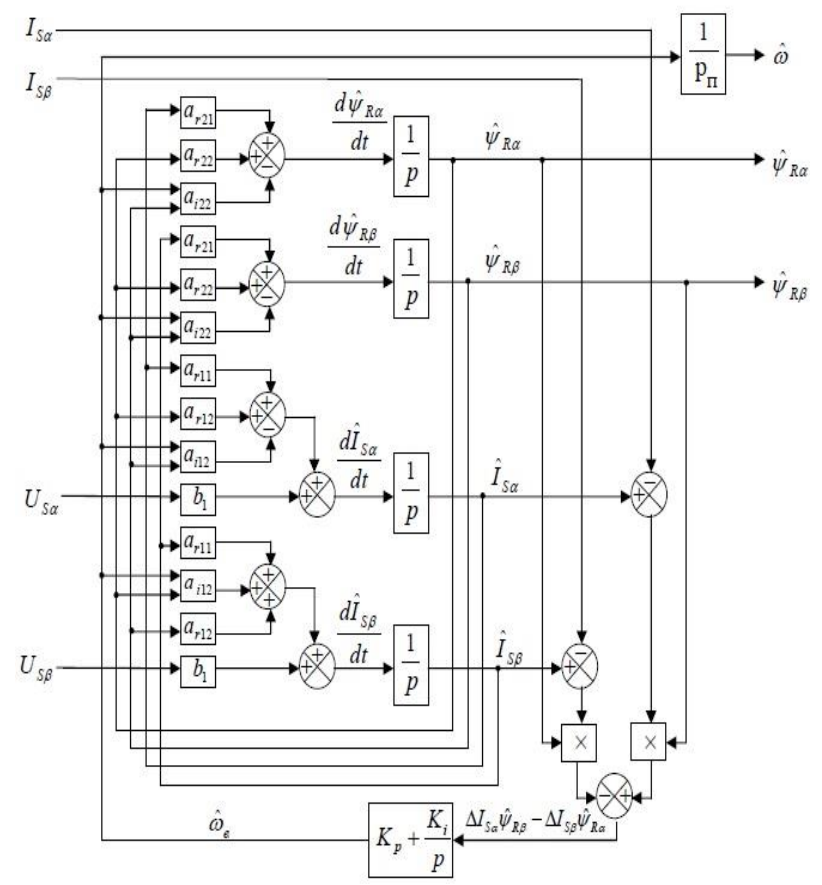

Fig. 8.Transition process of the torque.

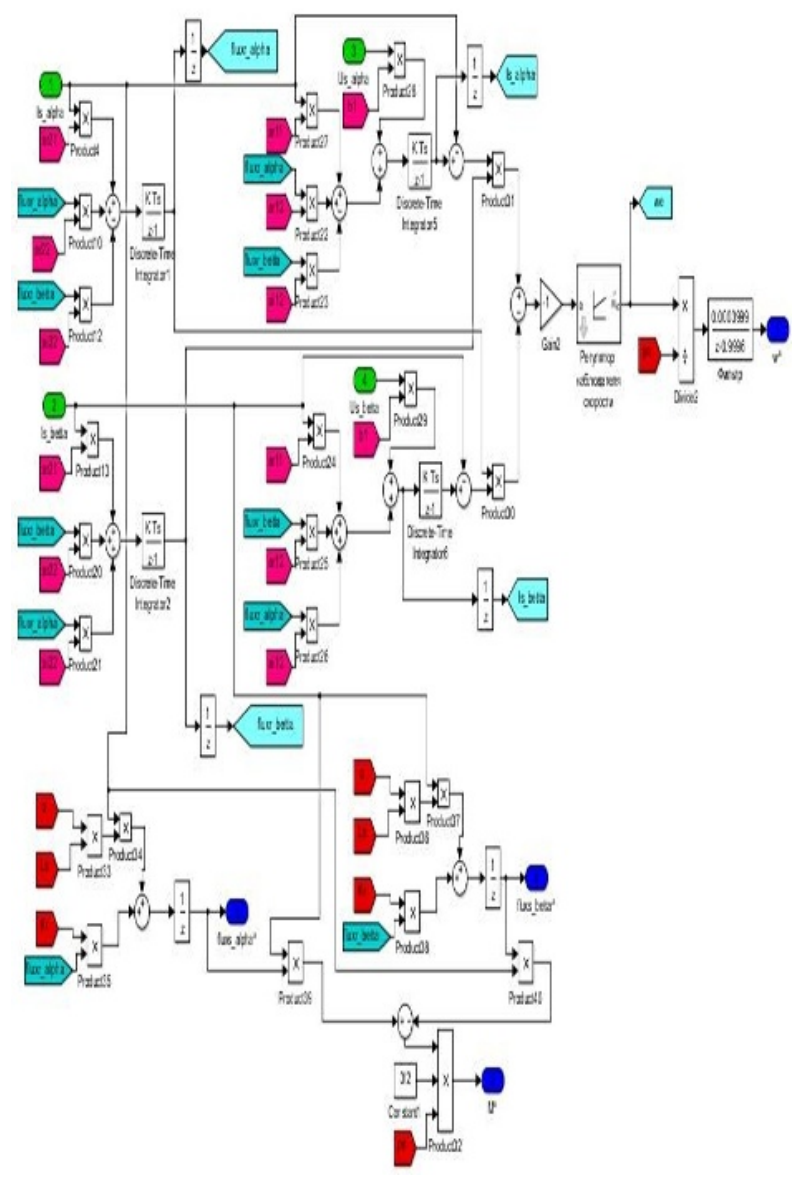

Fig. 9.Full-order observer simulation model.

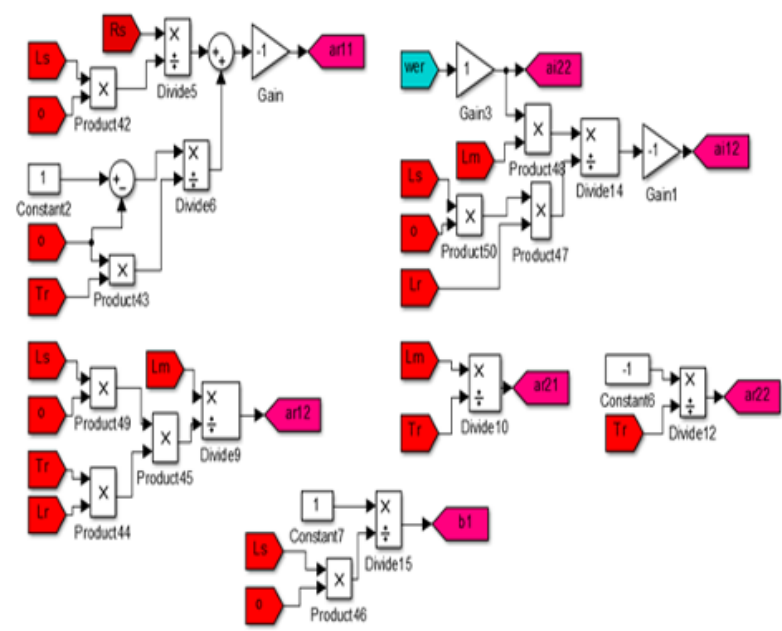

Fig. 10.Transient process of the speed.

\section{Simulation results}

\subsection{Direct torque control with a non-adaptive observer}

Transient processes in the angular speed of rotation frequency and electromagnetic moment in the system without an observer and with a non-adaptive observer are shown in Fig. 11, 12. 


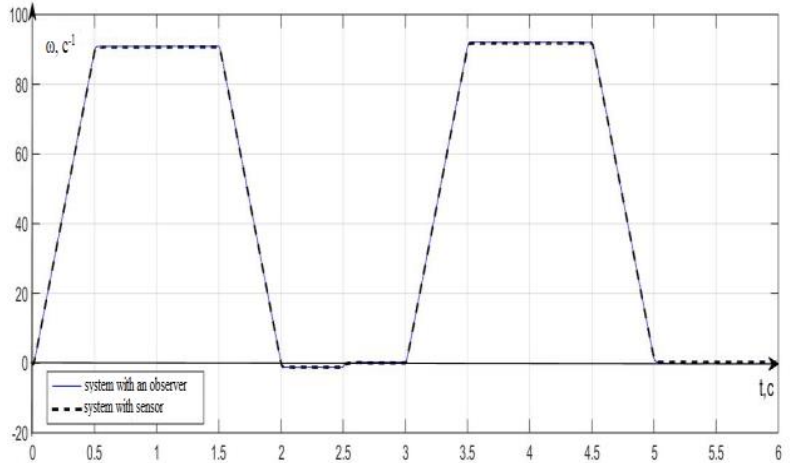

Fig. 11.Angular speed graph.

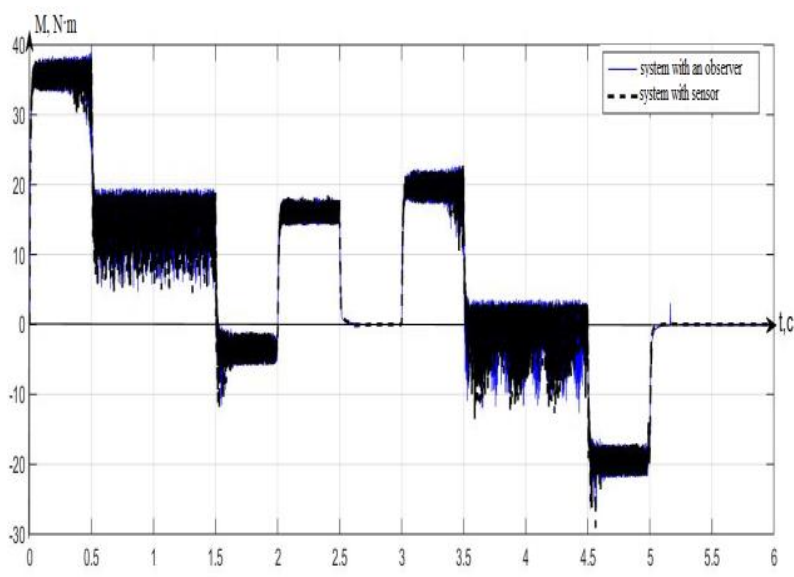

Fig. 12.Electromagnetic moment graph.

The simulation results prove the robustness of the implemented observer, since the observed values are determined quite accurately, the advantage of this type of observer is the simplicity and clarity of its interpretation, for the observer to work, only data from the stator current and voltage sensors are sufficient.

\subsection{Direct torque control with adaptive observer}

Transient processes in the angular velocity of rotation frequency and electromagnetic moment in the system without an observer and with an adaptive observer are shown in Fig. 13, 14.

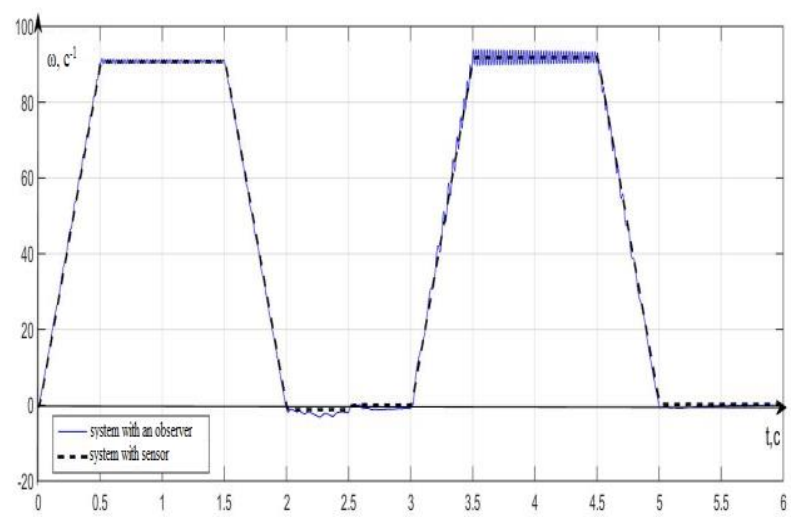

Fig. 13.Angular speed graph.

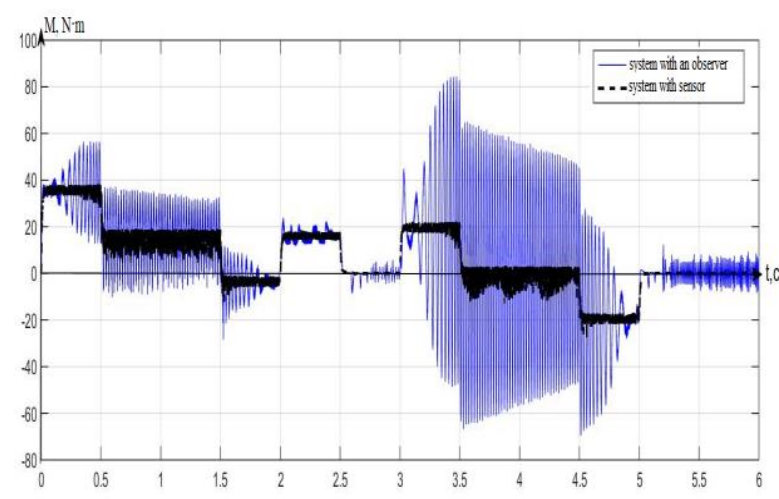

Fig. 14.Electromagnetic moment graph.

Based on the simulation results, it can be seen that the presence of low-frequency oscillations in the speed estimate signal leads to high-frequency torque oscillations. Therefore, this type of observer, although it provides work in the area of low and zero speeds, however, due to the presence of oscillations in the torque signal, cannot be used in the system.

\subsection{Direct torque control with full order observer}

Transient processes in the angular velocity of rotation frequency and electromagnetic moment in the system without an observer and with an adaptive observer are shown in Fig. 15, 16.

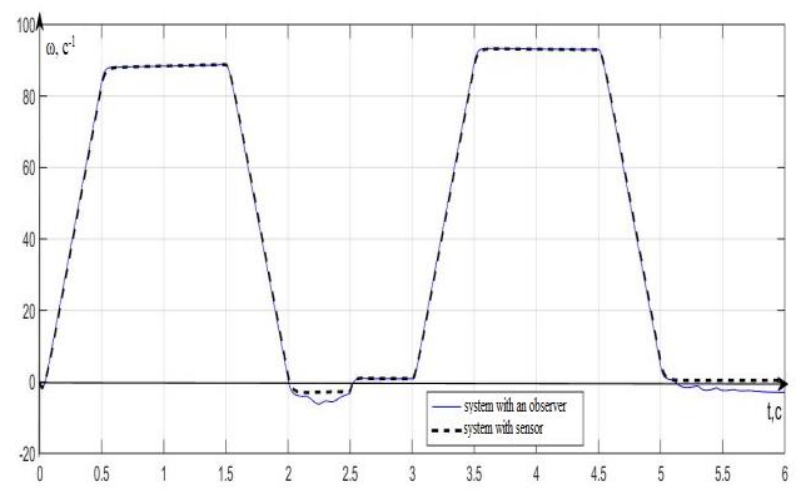

Fig. 15.Angular speed graph.

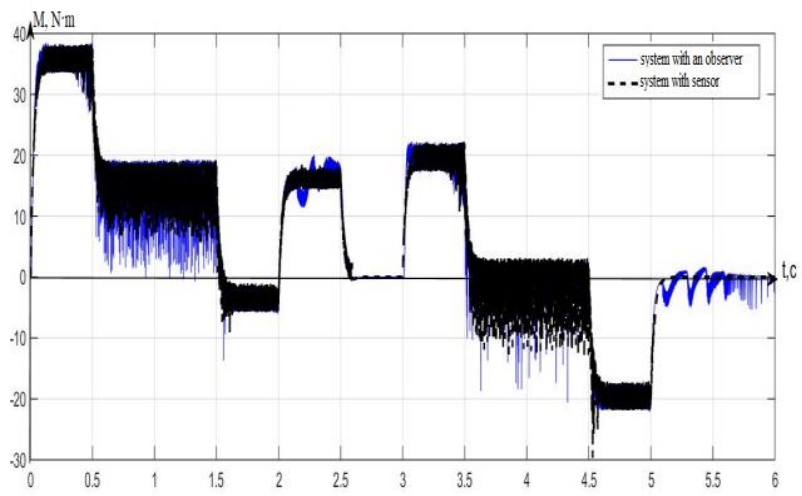

Fig. 16.Electromagnetic moment graph.

It can be seen from the graphs that the quality indicators of the control system with the developed 
observer of a complete order satisfy the requirements for the electric drive of the crane trolley.

\section{Conclusion}

On the basis of the simulation modeling, the advantages and disadvantages of various methods for constructing observers are revealed. The implemented sensorless control systems fulfill the required operating mode, providing smooth acceleration and deceleration of the electric motor, have a high speed of response and increased reliability.

\section{References}

[1] Y.I. Gracheva, N.A. Alimova, Calculating Methods and Comparative Analysis of Losses of Active and Electric Energy in Low Voltage Devices, International Ural Conference on Electrical Power Engineering (UralCon), 2019, 361-367 (2019)

[2] Y.I. Gracheva, O.V. Naumov, Estimation of Power Losses in Electric Devices of the Electrotechnical Complex, International Conference on Industrial Engineering, Applications and Manufacturing (ICIEAM), 6 (2019)

[3] V.N. Meshcheryakov, V.V. Danilov, Sh.R. Khasanov, S. Valtchev, Minimization of the stator current in induction motor with defined load on the shaft by maintaining optimum absolute slip, Kazan, SES 2019, E3S Web of Conferences, 01036 (2019)

[4] V.N. Meshcheryakov, D.V. Lastochkin, Z.M. Shakurova, S. Valtchev, Energy saving system of cascade variable frequency induction electric drive, Kazan, SES 2019, E3S Web of Conferences, 01037 (2019)

[5] V. Meshcheryakov, T. Sinykova, A. Sinyukov, A. Boikov, R. Mukhametzhanov, Modeling and analysis of vector control systems for asynchronous motor, High Speed Turbomachines and Electrical Dreves Conference 2020 (HSTED2020), Prague, Czech Republic, 01001 (09 July 2020)

[6] T.V. Sinykova, E.V. Sentsov, A.V. Sinyukov, Neural Network Speed Observers, Proceedings 2019 1st International Conference on Control Systems, Mathematical Modelling, Automation and Energy Efficiency (SUMMA), Lipetsk, Russia, 288 (2019)

[7] T.V. Sinykova, V.E. Gladyshev, A.V. Sinyukov, Methods for Reducing Electromechanical Oscillations in Conveyor Control Systems, Proceedings 2019 1st International Conference on Control Systems, Mathematical Modelling, Automation and Energy Efficiency (SUMMA), Lipetsk, Russia, 435 (2019)

[8] R.T.Y. Thien, Y. Kim, Decentralized Formation Flight via PID and Integral Sliding Mode Control,
Aerospace Science and Technology, Elsevier Science Publishing Company, Inc. 81, 322-332 (2018)

[9] Z. Hu, Y.V. Bodyanskiy, O.K. Tyshchenko, A Multidimensional Adaptive Growing Neuro-Fuzzy System and Its Online Learning Procedure, Advances in Intelligent System and Computing 689, 186-203 (2018)

[10] A. Pugachev, Efficiency increasing of induction motor scalar control systems, International Conference on Industrial Engineering, Applications and Manufacturing (ICIEM), St. Petersburg, Russia, 1-5 (16-19 May 2017)

[11] A.M. Abakumov, D.G. Randin, Research of DualMass Oscillation System with Linear Motor, International Conference on Industrial Engineering, Applications and Manufacturing (ICIEM), Sochi, Russia, 1-5 (25-27 March 2019)

[12] V. Meshcheryakov, D. Sibirtsev, E. Mikhailova, Mathematical Simulation of Synchronized Asynchronous Electric Drive, High Speed Turbomachines and Electrical Dreves Conference 2020 (HSTED-2020), Prague, Czech Republic, 01021 (9 July 2020)

[13] D.Yu. Kukishev, V.N. Meshcheryakov, V.N. Voyekov, I.V. Ivshin, Asynchronous electric drive with an additional switch in the DC link of the frequency converter, High Speed Turbomachines and Electrical Dreves Conference 2020 (HSTED2020), Prague, Czech Republic, 01043 (9 July 2020)

[13] Y.I. Gracheva, N.V. Chernova, A.I. Fedotov, E.A. Fedotov, Local Fourier transformation application for mathematic modeling of synchronous machine valve actuator, Journal of engineering and applied sciences 11, 1, 2939-2945 (2016)

[14] V.N. Meshcheryakov, D.S. Sibirtsev, Frequency asynchronous electric drive with correction of phase shift between moment-forming vectors, Control systems and information technologies 2, $68,48-57$ (2017) 